COMMENT. Carnitine supplementation was recommended in VPA-treated patients with hyperammonemia. The risk of VPA-induced Reye's-like syndrome could not be determined from this study.

\title{
VALPROATE-INDUCED LUPUS ERYTHEMATOSUS
}

A mentally retarded 30-year-old woman with partial trisomy of chromosome 9, suffering from epilepsy since age 11 months, developed systemic lupus erythematosus after one year of treatment with valproate (VPA) and ethosuximide (ESM) at the Clinica Neurologica, Universita di Roma Tor Vergata, Italy. When prednisone $1 \mathrm{mg} / \mathrm{kg} /$ day was administered and VPA gradually discontinued, clinical remission occurred within 10 days. The patient was maintained on ESM without relapse. (Gigli GL et al. Valproateinduced systemic lupus erythematosus in a patient with partial trisomy of chromosome 9 and epilepsy. Epilepsia June 1996;37:587-588). (Reprints: Dr GL Gigli, Clinica Neurologica, Universita di Roma Tor Vergata, Ospedale S Eugenio, Piazzale Umanesimo 10, 00144, Rome, Italy).

COMMENT. This was the fourth reported case of VPA-induced systemic lupus erythematosus. It presented with arthralgia, fever, and fatigue, after prolonged treatment. It resolved rapidly after discontinuing the drug.

\section{SEIZURE DISORDERS}

\section{PET BITEMPORAL HYPOMETABOLISM IN INFANTILE SPASMS}

A group of 18 infants (age range, 10 mo to $5 \mathrm{yr}$ ) with infantile spasms and a common metabolic pattern on positron emission tomography (PET) is reported from the Children's Hospital of Michigan, Wayne State University School of Medicine, Detroit, MI. CT and MRI scans were negative for focal abnormalities. EEGs showed bilateral or multifocal epileptogenicity. All had bilateral hypometabolism in the temporal lobes on PET. Analysis of outcome of 14 of the subjects at a mean follow-up of 4 years revealed 1) severe developmental delay; 2) absent language development; and 3) an autistic disorder in 10. The hypometabolic areas were thought to represent cortical dysplasias, but the patients were not considered candidates for cortical resection. (Chugani HT, Da Silva E, Chugani DC. Infantile spasms III. Prognostic implications of bitemporal hypometabolism on positron emission tomography. Ann Neurol May 1996;39:643-649). (Respond: Dr HT Chugani, Division of Pediatric Neurology and the PET Center, Children's Hospital of Michigan, 3901 Beaubien Blvd, Detroit, MI 48201).

COMMENT. Children with infantile spasms associated with bitemporal glucose hypometabolism on PET appear to comprise a homogeneous group having a poor prognosis, delayed development and severe dysphasia, and autism. They are not candidates for cortical resection. About $10 \%$ of children with infantile spasms are autistic.

PET in epilepsy is reviewed from the University Hospital Center of Liege, Belgium (Sadzot B. Epilepsia June 1996;37:511-514). The effect of valproate on cerebral metabolism and blood flow was investigated by deoxyglucose and 150 water PET at the NIH, Bethesda, MD (Gaillard WD etal. Epilepsia June 1996;37:515-521). VPA reduced regional cerebral blood flow but not cerebral metabolic rate for glucose in the thalamus, an effect associated with VPA's mechanism of action in generalized seizures. 